\title{
Single Layer Slot-Loaded Gap-Goupled Microstrip Array Antenna for Tri-Band Application
}

\author{
S. L. Mallikarjun \\ Department of Physics and Electronics, Maharashtra Udayagiri Mahavidyalaya, Udgir, India \\ Email: mslakshetty@rediffmail.com
}

How to cite this paper: Mallikarjun, S.L. (2021) Single Layer Slot-Loaded Gap-Goupled Microstrip Array Antenna for Tri-Band Application. Journal of Computer and Communications, 9, 59-65.

https://doi.org/10.4236/jcc.2021.91006

Received: December 28, 2020

Accepted: January 26, 2021

Published: January 29, 2021

\begin{abstract}
A novel method for tri-band microstrip array antenna with improvement in the bandwidth by incorporating wide slots and additional resonators which is gap-coupled to the non-radiating edges of a radiating element is presented. The experimental results show that two element slot-loaded gap-coupled microstrip array antenna gives a $-10 \mathrm{~dB}$ return loss bandwidth for three bands. The design specifications, radiation patterns and gain of the proposed antennas are presented and described.
\end{abstract}

\section{Keywords}

Tri-Band, Microstrip Array, Slot-Loading, Gap-Coupling, Corporate Feed

\section{Introduction}

This template Demand for compact and multifunctional wireless communication systems has spurred the development of multi-band and wide-band antennas with small size. Microstrip patch antennas are widely used as they offer compactness, low profile, light weight and economical efficiency. However, the microstrip patch antenna is limited by its narrow operating bandwidth. There are numerous and well known methods to increase the bandwidth of microstrip patch antennas, including increase in the substrate thickness, the use of a low dielectric substrate [1], the use of various impedance matching and feeding techniques [2], the use of multiple resonators [3] [4] [5] [6] and the use of slot antenna geometry [7]. However, the bandwidth and the size of an antenna has generally mutually conflicting properties, that is, improvement of one of the characteristics normally results in degradation of the other. However, a single layer slot-loaded gap-coupled microstrip array configuration for enhancing the 
bandwidth is found rarely.

In this paper, a new configuration has been proposed for tri-band operation without increasing the effective area. The concept of slot-loading and gap-coupling is used for designing a single layer two element linear array and the obtained experimental results are presented and discussed.

\section{Design Specifications}

The proposed antenna is designed using low cost glass epoxy substrate material having dielectric constant $\varepsilon_{\mathrm{r}}=4.2$ and thickness $\mathrm{h}=0.16 \mathrm{~cm}$. The geometry of two element slot-loaded gap-coupled microstrip array antenna (TSGMSAA) is shown in Figure 1.

The dimensions of elements of array are $\mathrm{L}=0.66 \mathrm{~cm}$ and $\mathrm{W}=0.98 \mathrm{~cm}$. A rectangular wide slot of optimized dimensions $\mathrm{L}_{\mathrm{S}}=0.33 \mathrm{~cm}$ and $\mathrm{W}_{\mathrm{S}}=0.22 \mathrm{~cm}$ is placed at each edge of second element which results into plus shape [8] [9]. The dimensions of wide slots are taken in terms of $\lambda_{0}$, where $\lambda_{0}$ is the free space wavelength in $\mathrm{cm}$. These slots are considered as wide slots as their width is comparable to their length. The wide slot is selected because it is more effective in enhancing the impedance bandwidth than the narrow slot [10]. A common parasitic element of dimension $\mathrm{Lp}=0.66 \mathrm{~cm}$ and $\mathrm{Wp}=1.72 \mathrm{~cm}$ is placed between non-radiating edges of radiating elements, which forms the non-radiating edge gap-coupling. The distance between the parasitic and radiating element $S$ is optimized and is taken as $0.025 \lambda \mathrm{g}$, where $\lambda \mathrm{g}$ is the operating wavelength in $\mathrm{cm}$ [11]. The length $\mathrm{Lg}=3.44 \mathrm{~cm}$ and width $\mathrm{Wg}=6.38 \mathrm{~cm}$ of the ground plane of antenna is calculated using $\mathrm{Lg}=6 \mathrm{~h}+\mathrm{L}$ and $\mathrm{Wg}=6 \mathrm{~h}+\mathrm{W}$ [11]. The elements of this array antenna are excited through simple corporate feed arrangement. This feed arrangement consist of matching transformer, quarter wave transformer,

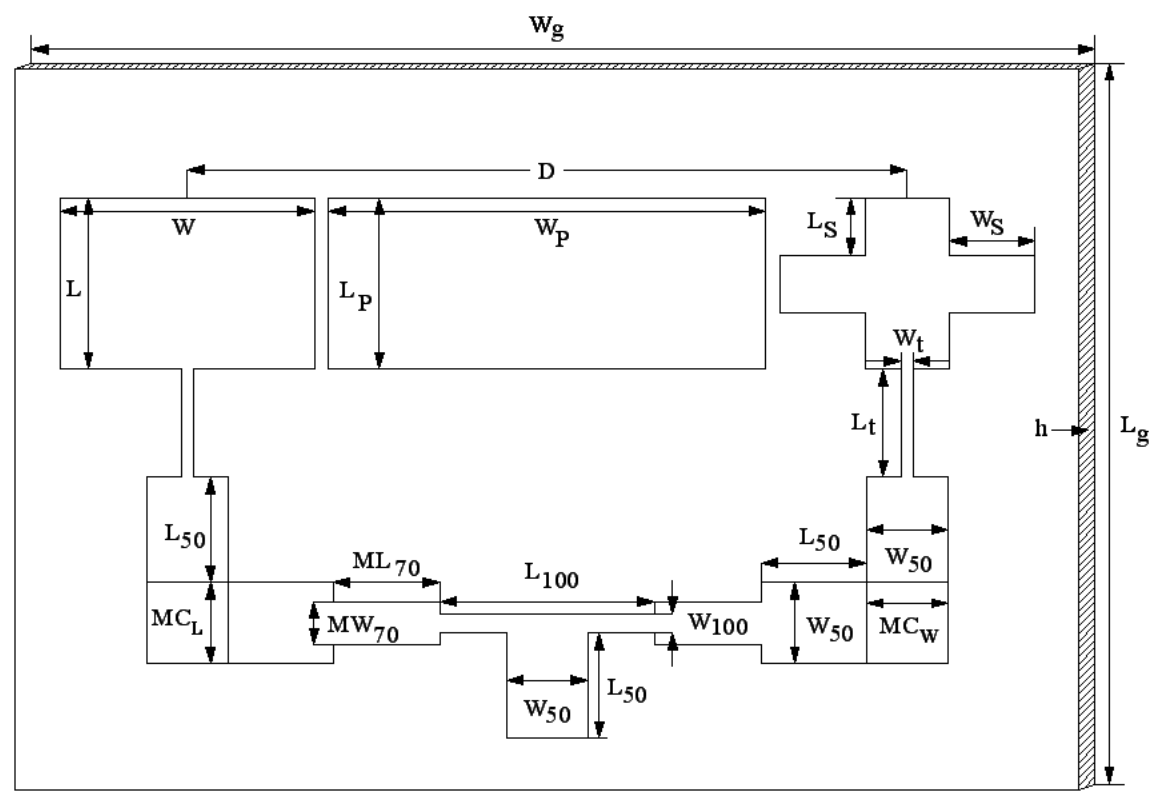

Figure 1. Geometry of TSGMSAA. 
microstrip coupler and power divider for better impedance matching between feed and radiating elements [12]. A two-way power divider made up of $70 \Omega$ matching transformer of dimension $\mathrm{L}_{70}=0.41, \mathrm{~W}_{70}=0.16 \mathrm{~cm}$ is used between $100 \Omega$ microstrip line of dimension $\mathrm{L}_{100}=0.83, \mathrm{~W}_{100}=0.07 \mathrm{~cm}$ and $50 \Omega$ microstrip line of dimension $\mathrm{L}_{50}=0.41, \mathrm{~W}_{50}=0.32 \mathrm{~cm}$. A microstrip coupler of dimension $\mathrm{MC}_{\mathrm{L}}=\mathrm{MC}_{\mathrm{W}}=0.32 \mathrm{~cm}$ is used between $50 \Omega$ microstrip lines to couple the power [13-14]. The $50 \Omega$ microstrip line is connected at the center of the driven element through a quarter wave transformer of dimension $\mathrm{Lt}=0.42 \mathrm{Wt}$ $=0.05 \mathrm{~cm}$ for better impedance matching. At the tip of microstrip line feed of 50 $\Omega$, a coaxial SMA connector is used for feeding the microwave power. The array elements are kept at a distance of $\mathrm{D}=2.79 \mathrm{~cm}$ from their center point. This optimized distance is selected in order to add the radiated power in free space [15].

\section{Experimental Results and Discussion}

The impedance bandwidths over return loss less than $-10 \mathrm{~dB}$ for the proposed antennas are measured. The measurements are taken on Vector Network Analyzer (Rohde \& Schwarz, German make ZVK Model No. 1127.8651). The variation of return loss versus frequency of TSGMSAA is shown in Figure 2.

From Figure 2, it is observed that TSGMSAA offers tri-band in the range 8 $\mathrm{GHz}$ to $14 \mathrm{GHz}$ at $8.44 \mathrm{GHz}, 9.84 \mathrm{GHz}$, and $13.03 \mathrm{GHz}$ with a magnitude of 630 $\mathrm{MHz}$ (7.37\%), $320 \mathrm{MHz}$ (3.24\%) and $1090 \mathrm{MHz}$ (8.40\%) respectively. The obtained bandwidths are more compared to single radiating element $(2.85 \%)$. The first band is obtained from element which is gap-coupled to the non-radiating edge and improvement in the impedance bandwidth is due to wider patch dimension [16]. The second band is due the fundamental resonance of the first element excited through corporate feed network, as it is resonating at $9.84 \mathrm{GHz}$

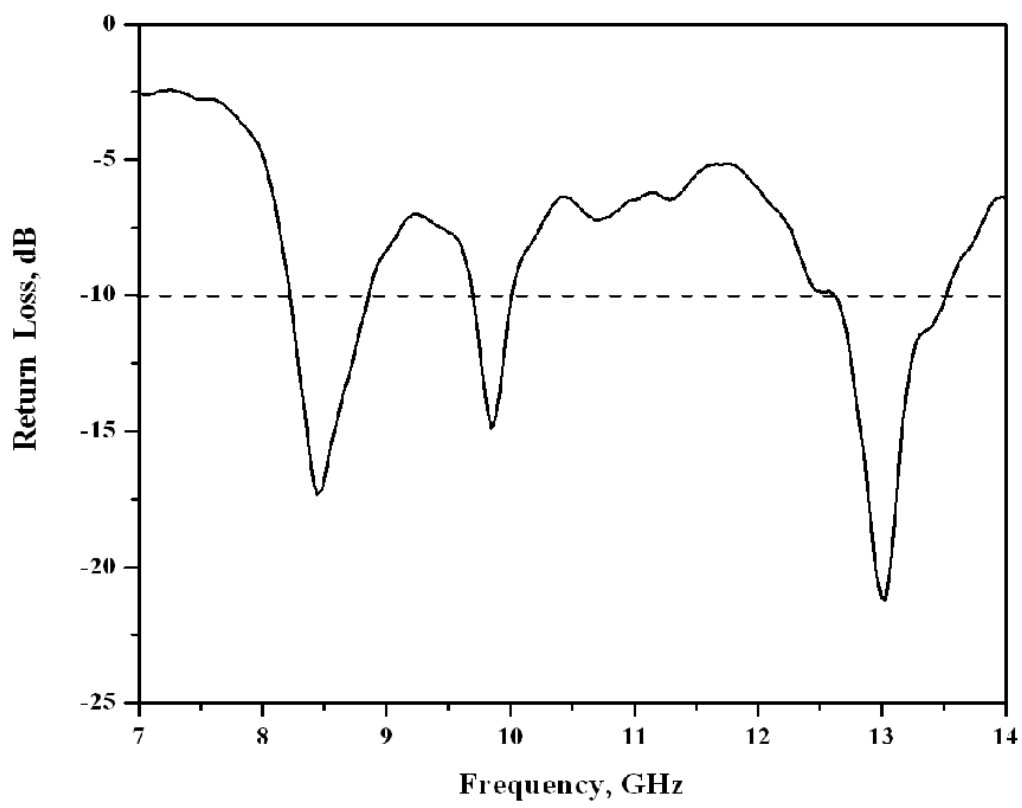

Figure 2. Variation of return loss versus frequency. 
proves that the impedance is matching to $50 \Omega$. The third band is due to the second element, which is also excited through corporate feed network and shift in frequency and improvement in impedance bandwidth is due to embedding of wide slots at appropriate place resonate nearer to the fundamental resonance of radiating elements [11]. The return loss measured at resonating frequencies is $-17.33 \mathrm{~dB}$ at $8.44 \mathrm{GHz},-14.89 \mathrm{~dB}$ at $9.84 \mathrm{GHz}$ and -21.21 at 13.03 respectively.

The H-plane co-polar and cross-polar radiation patterns of TSGMSAA are measured at their resonating frequencies and are shown in Figures 3-5. These figures indicate that the antenna shows broad side radiation characteristics. Figure 5 shows the radiation pattern measured at $13.03 \mathrm{GHz}$. At this frequency antenna shows split beam radiation pattern which is useful in SAR for

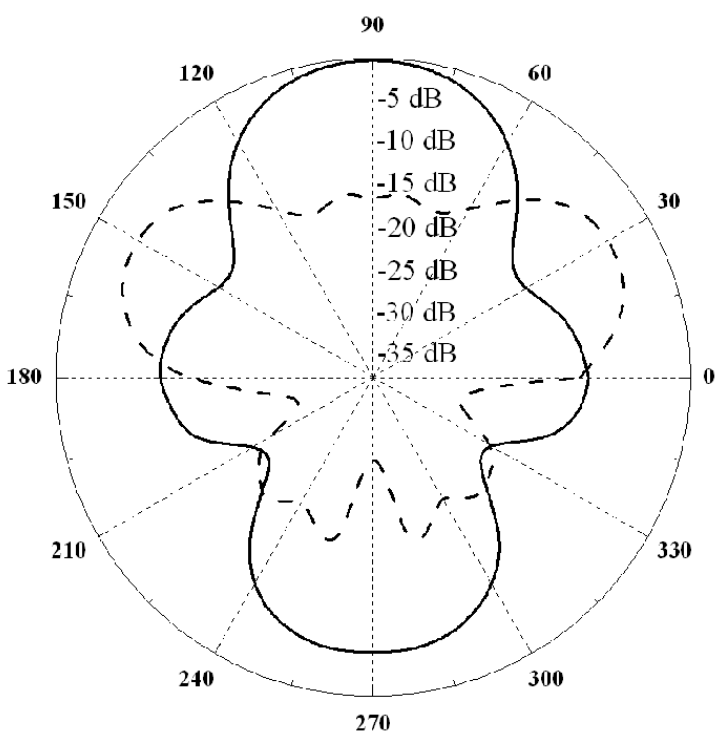

Figure 3. Variation of relative power versus azimuth angle at $8.44 \mathrm{GHz}$.

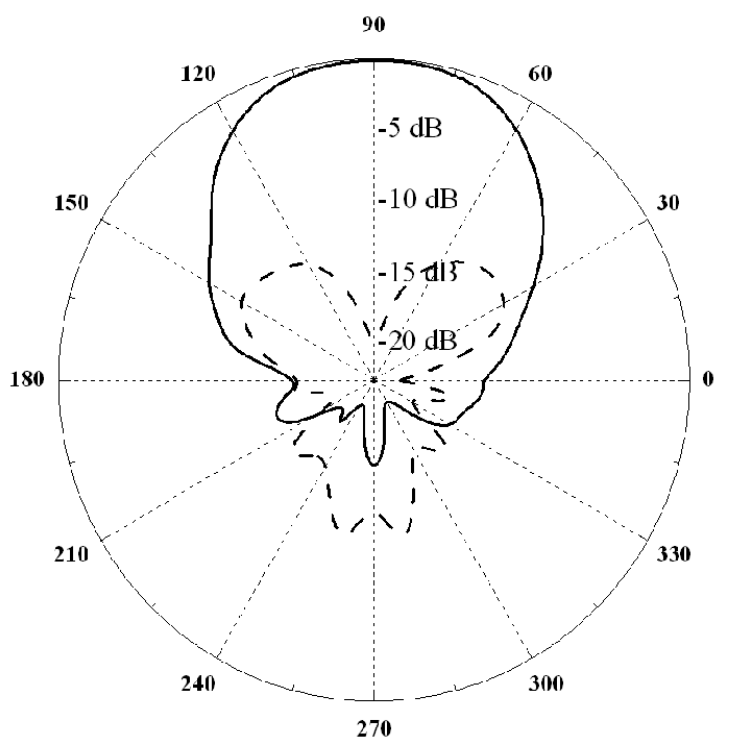

Figure 4. Variation of relative power versus azimuth angle at $9.84 \mathrm{GHz}$. 
generating a pair of forward and backward squinted beams and provides simultaneous measurement of both the along-track and the cross-track velocities [17].

The half power beam widths (HPBWs) of TSGMSAA are calculated for the resonating frequencies and are found to be $46^{\circ}$ and $69^{\circ}$ for $8.44 \mathrm{GHz}$ and 9.84 $\mathrm{GHz}$ respectively.

The gain of TSGMSAA is calculated at the resonating frequencies and the variation of gain with respect to frequency is shown in Figure 6. This shows the use of slots and additional resonators gap-coupled to array configuration also improves the antenna gain considerably [5].

The variation of input impedance of the proposed antenna is shown in Figure 7.

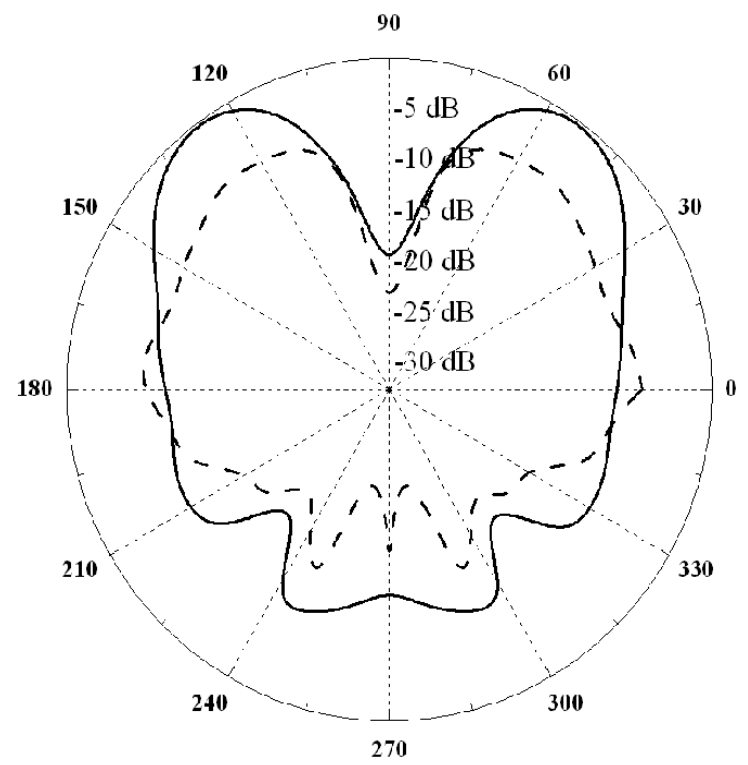

Figure 5. Variation of relative power versus azimuth angle at $13.03 \mathrm{GHz}$.

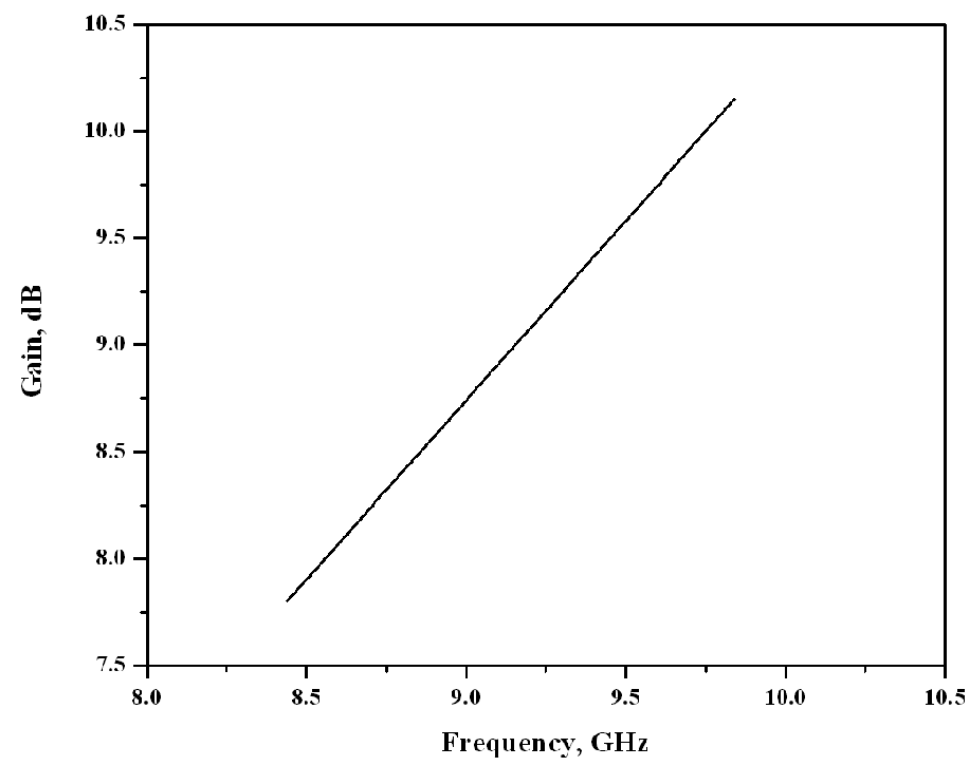

Figure 6. Variation of gain versus frequency. 


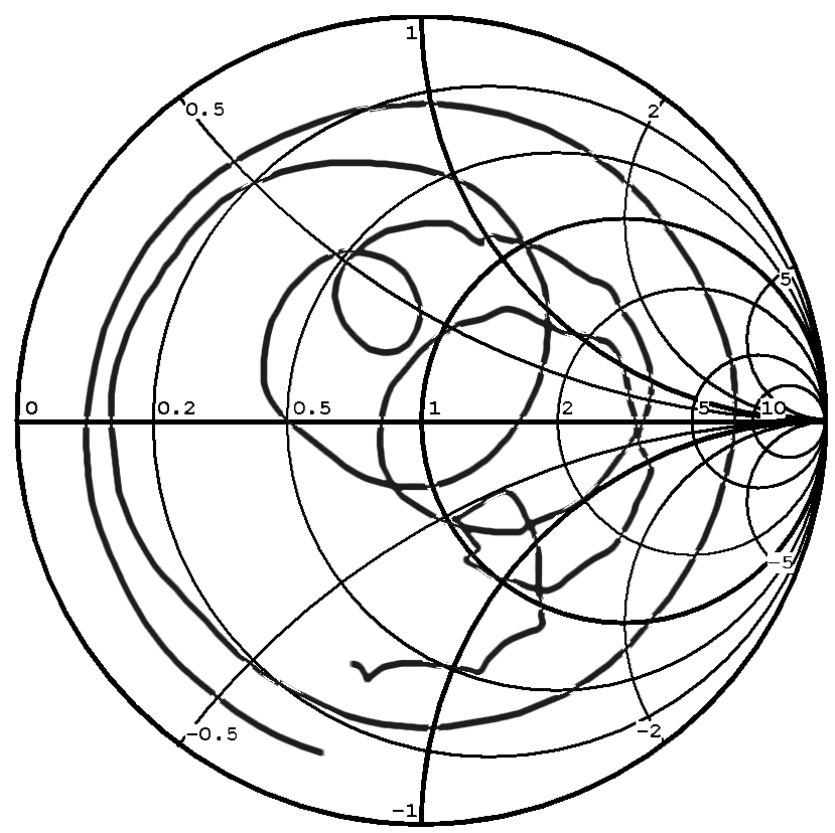

Figure 7. Input impedance profile of ESGMSAA.

It is seen that the input impedance has multiple loops at the center of Smith chart that validates its tri-band operation.

\section{Conclusion}

The detailed experimental study shows that, the antenna is quite simple in design and fabrication and quite good in enhancing the impedance bandwidth and gives better gain with broadside radiation pattern at the resonating frequencies. This tri-band microstrip patch array antenna may provide an alternative to large bandwidth planar antennas in applications in which large bandwidths are needed for operating at two separate transmit-receiver bands. When the two operating frequencies are far apart, a tri-band patch array structure can be conceived to avoid the use of separate antennas. The proposed antenna is also superior as it uses single layer, low cost substrate material and finds applications in modern communication system, microwave wireless communication system and in radar communication systems particularly in monopulse tracking radar and SAR.

\section{Acknowledgements}

Thanks to Prof. P. V. Hunagund, Dean Faculty of Science and Technology and Prof. P. M. Hadalgi, Department of Applied Electronics, Gulbarga University, Kalburgi, for providing experimental facility and fruitful discussion.

\section{Conflicts of Interest}

The author declares no conflicts of interest regarding the publication of this paper. 


\section{References}

[1] Schaubert, D.H., Pozar, D.M. and Adrian, A. (1989) Effect of Microstrip Antenna Substrate Thickness and Permittivity. IEEE Trans. Antennas Propog., AP-37, 677-682. https://doi.org/10.1109/8.29353

[2] Pues, H.F. and Van De Capelle, A.R. (1989) An Impedance-Matching Technique for Increasing the Bandwidth of Microstrip Antennas. IEEE Trans. Antennas Propog., AP-37, 1345-1354. https://doi.org/10.1109/8.43553

[3] Pozar, D.M. and Schaubert, D.H. (1995) Microstrip Antennas. IEEE Press, New York, 155-166. https://doi.org/10.1109/9780470545270

[4] Wi, S.-H., Lee, Y.-S. and Yook, J.-G. (2007) Wideband Microstrip Patch Antenna with U-Shaped Parasitic Elements. IEEE Trans. Antennas Propog., 55, 1196-1199. https://doi.org/10.1109/TAP.2007.893427

[5] Mallikarjun, S.L., Madhuri, R.G., Malipatil, S.A. and Hadalgi, P.M. (2009) Development of Microstrip Array Antenna for Wideband and Multiband Applications. Indian Journal of Radio and Space Physics, 38, 289-294.

[6] Mallikarjun, S.L. and Hadalgi, P.M. (2010) Single Layer Modified Rectangular Microstrip Array Antenna for Multi Band and Wide Band Applications. Indian Journal of Radio and Space Physics, 39, 156-162.

[7] Chair, R., Mak, C.-L., Lee, K.F., Luk, K.-M. and Kishk, A.A. (2005) Miniature Wide-Band Half U-Slot and Half E-Shaped Patch Antenna. IEEE Trans. Antennas Propog., 53, 2645-2652. https://doi.org/10.1109/TAP.2005.851852

[8] Mallikarjun, S.L., Madhuri, R.G., Malipatil, S.A. and Hadalgi, P.M. (2008) Compact High Gain Multi Frequency Antenna. IEEE-Int. Symp. on Microwaves, 369-373.

[9] Mallikarjun, S.L., Hadalgi, P.M., Malipatil, S.A. and Hunagund, P.V. (2011) Development of Compact Microstrip Array Antennas with DGS for Broader Bandwidth and Beam. International Journal of Electronics Engineering, 3, 25-27.

[10] Bhal, I.J. and Bhartia, P. (1980) Microstrip Antennas. Artech House, New Delhi, 230-234.

[11] Kumar, G. and Ray, K.P. (2003) Broadband Microstrip Antennas. Artech House, London, 89-110.

[12] Lee, K.F. and Chen, W. (1997) Advances in Microstrip and Printed Antennas. John Wiley, New York.

[13] Jong Kim, I.I. and Yoon, Y.J. (2000) Design of Wideband Microstrip Array Antenna Using the Coupled Lines. IEEE Antenna and Prop. Soci. Int. Symp., 3, 1410-1413.

[14] Oing, X.M. and Chia, Y.W.M. (1999) Circularly Polarized Circular Ring Slot Antenna Fed by Stripline Hybrid Coupler. Elect. Lett., 35, 2154-2155.

https://doi.org/10.1049/el:19991474

[15] Constantine Balanies, A. (1982) Antenna Theory Analysis and Design. John Wiley \& Sons Inc. New York.

[16] Aanandan, C.K., Mohanan, P. and Nair, K.G. (1990) Broad-Band Gap Coupled Microstrip Antenna. IEEE Trans. Antennas Propog., 38, 1581-1586.

https://doi.org/10.1109/8.59771

[17] Huang, J. and Madsen, S.N. (1992) A Dual Beam Microstrip Array Antenna. IEEE Antenna and Prop. Soci. Int. Symp., 1, 147-150.

https://doi.org/10.1109/APS.1992.221980 